\title{
Uma investigação dos efeitos do ensino explícito da pronúncia na aula de inglês como língua estrangeira ${ }^{1}$
}

\author{
An investigation of the effects of explicit \\ pronunciation instruction in the English as a \\ foreign language class
}

Ronaldo Mangueira Lima Júnior*

Universidade de Brasília

RESUMO: O presente estudo investigou os efeitos, e sua durabilidade, do ensino explícito da pronúncia em aulas de inglês como língua estrangeira. Foi conduzida uma pesquisa-ação intervencionista com duas turmas de aprendizes pré-adolescentes do nível básico de inglês. Em uma das turmas houve intervenção de aulas explícitas de pronúncia semanais durante um semestre. Todos os participantes foram gravados uma vez antes e duas vezes após as intervençōes e suas gravações foram transcritas e analisadas foneticamente. Os resultados indicam, entre outras conclusōes, que há efeitos positivos na instrução explícita da pronúncia e que esses efeitos são duráveis.

PALAVRAS-CHAVE: fonética; fonologia; aquisição de segunda língua; instrução explícita.

ABSTRACT: This study investigated the effects of explicit instruction, and their durability, in English as a foreign language classes. An interventionist action research was carried out with two classes of basic level, adolescent learners of English as a Foreign Language. In one of the classes there was intervention of weekly explicit lessons of pronunciation for one semester. All participants were recorded once before and twice after the interventions and all their recordings were phonetically transcribed and analyzed. The results indicate that, among other conclusions, there are positive effects of explicit pronunciation teaching and that these effects are durable.

KEYWORDS: phonetics; phonology; second language acquisition; explicit instruction.

\footnotetext{
${ }^{1}$ Pesquisa conduzida para obtenção do título de mestre no Programa de Pós-Graduação em Linguística Aplicada da Universidade de Brasília, com orientação do Prof. Dr. Gilberto Antunes Chauvet e com conclusão e defesa em dezembro de 2008.

* ronaldo.limajr@gmail.com
} 


\section{Introdução}

A maioria dos livros didáticos utilizados nas escolas e nos institutos de línguas no Brasil é produzida por editoras internacionais, que os produzem visando ao público mundial, tomando como base alunos falantes das mais variadas línguas. Com o ensino da pronúncia, a situação não é diferente, e generalizar seu ensino em um ambiente onde os aprendizes têm a mesma língua materna (L1) - como é o caso no Brasil - é não apenas um investimento de tempo desnecessário como também uma maneira de entediar os alunos, com muitas tarefas que apresentam grau zero de desafio. Um bom exemplo é quando livros didáticos apresentam uma lição de pronúncia contrastando os sons [v] e [b] (e.g. van e ban). A escolha de incluir essa lição é inspirada na dificuldade que hispano-falantes têm em distinguir esses sons. Contudo, tanto o professor como o aluno brasileiro podem se sentir imbecilizados ao praticarem esse contraste, uma vez que a distinção $[v]$ e [b] existe no português e não causa dificuldade aos seus falantes aprendendo inglês. Outro exemplo seria uma lição que contrasta [r] e [1] (e.g. rate e late), baseada na dificuldade que falantes do japonês têm pelo fato do fonema /1/ não integrar a fonologia dessa língua, visto que o segmento [1] existe no japonês apenas como alofone em distribuição complementar de [r].

Como consequência, professores e alunos de inglês brasileiros podem lançar descrédito às tarefas de pronúncia oriundas de (seus) livros didáticos produzidos para o público internacional, muitas vezes optando por ignorar essas atividades. Deixar de fazer exercícios de pronúncia, entretanto, pode tornar-se um perigoso hábito, pois, já que o livro didático falha em providenciar exercícios significativos e específicos o suficiente para seus alunos, professores de inglês para brasileiros correm o risco de passarem a ver o ensino da pronúncia como menos importante ou como a parte do livro que pode ser ignorada, caso seja preciso, conforme apontam Kelly (2000, p. 13) - que diz ser um dos problemas-chave do ensino da pronúncia o fato de ela ser negligenciada - e Yule e MacDonald (1994, p. 111), ao admitirem que "muitos no campo do ensino de línguas parecem sentir que o ensino da pronúncia tem pouco efeito observável e que o tempo em sala de aula pode ser mais efetivamente utilizado para forjar outros aspectos da L2". ${ }^{2}$

\footnotetext{
2 "Many in the language-teaching field seem to feel that pronunciation teaching has little observable effect and that classroom time can be more effectively devoted to fostering other aspects of the L2".
} 
Portanto, o professor de inglês no Brasil pode (e deve) beneficiar-se da homogeneidade que há entre seus alunos com relação à língua materna, principalmente no tocante ao ensino da pronúncia, selecionando pontos específicos que causam dificuldades a alunos luso-falantes brasileiros pelas características de sua L1. Afinal, "em salas de aula [...] onde professores compartilham uma língua nativa com seus alunos, os professores precisam considerar cuidadosamente como eles podem fazer o melhor uso da língua nativa de seus alunos para expandir suas competências em inglês"3 (MCKAY, 2005, p. 296-297).

Sendo assim, instigada pelas situaçôes supramencionadas, a pesquisa aqui relatada teve por objetivo investigar os efeitos do ensino explícito de aspectos segmentais ${ }^{4} \mathrm{da}$ pronúncia do inglês que são problemáticos para os alunos luso-falantes na sala de aula de inglês como língua estrangeira $(\mathrm{LE})^{5}$ no Brasil.

As seguintes perguntas de pesquisa guiaram a investigação:

1. quais são os efeitos do ensino explícito da pronúncia na aula de inglês como LE sobre a aquisição dos aspectos fonético-fonológicos dessa LE?;

2. caso haja efeitos positivos da instrução explícita, qual é a durabilidade desses efeitos?

Vale esclarecer que os termos pronúncia e aspectos fonético-fonológicos serão os utilizados, uma vez que a aquisição da pronúncia de uma L2 está na interface entre a fonética e a fonologia. $\mathrm{O}$ foco do ensino da pronúncia de uma

\footnotetext{
3 "in classrooms [...] where teachers share a first language with their students, teachers need to carefully consider how they can best make use of their students' first language to further their competency in English".

${ }^{4}$ Os aspectos segmentais da fonologia são os sons (vogais e consoantes) isolados. Já os suprassegmentais estão relacionados aos aspectos do discurso conectado, como entoação, acento e ligações entre sons, entre outros. Nesta pesquisa foram investigados apenas os aspectos segmentais para limitar o escopo da pesquisa, tornando-a mais factível.

${ }^{5} \mathrm{O}$ termo Língua Estrangeira (LE) será utilizado para o contexto de aprendizagem de uma língua que não a nativa em um país onde essa língua não é falada como L1, como o de aprendizagem do inglês no Brasil. Já a sigla L2 será utilizada como termo guarda-chuva, designando uma língua que não a nativa, não importando a modalidade de aquisição (LE ou imersão).
} 
L2 é sua fonologia, pois o objetivo principal de um aluno é o de transmitir significado por meio dos sons da L2. Contudo, há situações fonéticas da L2 que necessitam de tratamento no ensino da pronúncia, como o caso da aspiração das oclusivas surdas em início de sílaba tônica no inglês - fenômeno fonético no inglês, e não fonológico devido à sua natureza alofônica, mas que gera dificuldade de compreensão se mal pronunciados. Portanto, será utilizada neste artigo a transcrição dos segmentos, entre colchetes; sendo utilizada a transcrição de fonemas, entre barras, apenas quando a referência a um fonema seja explicitamente necessária.

\section{Fundamentação teórica}

Esta pesquisa teve como bases teóricas principais a questão do ensino da pronúncia e da instrução explícita.

\section{Ensino da Pronúncia}

O domínio da pronúncia de uma L2 é imprescindível para um bom comando dela. Celce-Murcia, Brinton e Goodwin (1996, p. 7), por exemplo, mencionam um nível limiar para a pronúncia do inglês para não nativos. De acordo com as autoras, "se [falantes não nativos] se encaixarem abaixo desse limiar, eles terão problemas de comunicação oral, não importando o quão excelente ou extenso seja seu controle da gramática e do vocabulário do inglês" . ${ }^{6}$ Também Morley (1994, p. 67), além de iniciar seu artigo afirmando que a pronúncia é criticamente importante, declara, na introdução de sua antologia de artigos sobre pedagogia e teoria da pronúncia, que "pronúncia inteligível é um componente essencial da competência comunicativa" (MORLEY, 1994, p. 1). Ainda Pennington (1996, p. 2) aponta os sons, por serem "a base de todas as unidades lingüísticas superiores", 8 como os responsáveis pela diferenciação de significado lexical, gramatical e até mesmo pragmático.

Além disso, são inumeráveis os exemplos em forma de anedota de situações frustrantes, e até constrangedoras, que aprendizes de uma língua

\footnotetext{
6 "if they fall below this threshold level, they will have oral communication problems no matter how excellent and extensive their control of English grammar and vocabulary might be".

7 "intelligible pronunciation is an essential component of communicative competence".

8 "sounds are the basis of all higher linguistic units".
} 
podem passar por não terem o comando necessário da sua pronúncia. Kelly (2000, p. 11), por exemplo, imagina um aprendiz em um restaurante pedindo soap em vez de soup, ${ }^{9}$ devido à falta de controle da pronúncia, o que, sustentando a posição de Pennington (1996), representa uma diferença léxica causada por um som mal pronunciado. Também Celce-Murcia, Brinton e Goodwin (1996) imaginam um turista nos Estados Unidos pedindo batter em vez de butter $^{10} \mathrm{e}$ recebendo, no lugar de manteiga, um olhar estranho. Imagine, por último, um aprendiz de inglês querendo dizer "I saw a sheep in the farm" 11 mas troca o fonema /i:/ por / I/ - em sua mente trocando "apenas um sonzinho". Nesse caso, a comunicação é completamente prejudicada, pois ele acabará dizendo que viu um navio na fazenda.

A falta de conhecimento fonético-fonológico da L2 aprendida pode, portanto, prejudicar as tentativas de comunicação, deflagrando, assim, a necessidade de haver foco no ensino da pronúncia na sala de L2. Portanto, uma vez que "o objetivo mais óbvio, justificável e urgente na área da fonologia éa inteligibilidade"12 (PENNINGTON, 1996, p. 220 - grifo do original) e já que ser inteligível é um pressuposto para a comunicação eficaz, o objetivo final desta pesquisa se sobrepóe ao do ensino da pronúncia, isto é, o de propiciar mais oportunidades para uma comunicação de sucesso em uma L2.

\section{A Instrução Explícita}

Há uma série de estudos que tratam dos efeitos do ensino explícito à aquisição de uma L2. Neufeld (1978), por exemplo, demonstra que, com o ensino da pronúncia, é possível que até mesmo adultos cheguem a um nível de pronúncia bem próximo ao de falantes nativos. Dos seus vinte alunos (adultos) anglófonos que receberam 18 horas de instrução intensiva sobre a pronúncia de Chinês e Japonês, apenas três não foram julgados como "nativos" por juízes nativos das línguas testadas. Apesar de algumas críticas metodológicas que esse estudo recebeu, "elas não refutam a afirmação essencial que Neufeld quer fazer, qual seja, a de que é possível para adultos alcançarem níveis de

\footnotetext{
${ }^{9}$ Sabão em vez de sopa.

${ }^{10}$ Massa (para empanar) em vez de manteiga.

11 "Eu vi uma ovelha na fazenda."

12 "the most obvious, justifiable and pressing goal in the area of phonology is intelligibility".
} 
proficiência de nativos em uma L2"13 (ELLIS, 1994, p. 486-487). Para esta pesquisa, o estudo de Neufeld também demonstra o poder que o ensino explícito e intensivo da pronúncia pode ter sobre sua aquisição.

Bongaerts (1999, p. 154-155) também oferece suporte ao benefício da instrução explícita. Ele sugere que um dos motivos de sucesso de seus participantes de pesquisa é que "todos eles receberam intenso treinamento perceptivo que focalizava sua atenção nos contrastes fonéticos sutis entre os sons da fala da língua-alvo e da L1", ${ }^{14}$ exatamente o tipo de instrução conduzida nas intervençóes desta pesquisa. $\mathrm{O}$ autor ainda afirma que os participantes que receberam mais instrução tiveram resultados melhores.

Além desses dois casos específicos sobre o ensino da pronúncia, é possível encontrar uma vasta gama de estudos sobre a eficiência da instrução formal (ou ensino explícito) na sala de aula de línguas. Long (1983) fez uma revisão do tema com os principais estudos publicados até 1983, analisando um total de 11 publicações. Sua conclusão geral é de que "existe evidência considerável para indicar que a instrução de L2 faz, sim, diferença" ${ }^{15}$ (LONG, 1983, p. 374).

Uma revisão mais recente de estudos sobre esse assunto foi feita por Norris e Ortega (2000). Os autores encontraram 250 estudos sobre o tema, publicados entre 1980 e 1998 e, ao fazerem uma "meta-análise quantitativa" dos 49 artigos que consideraram possuir dados suficientes, os autores concluíram que a revisão "indicou que a instrução focalizada de L2 resulta em grandes ganhos dos objetivos, que os tipos explícitos de instrução são mais efetivos do que os tipos implícitos" 16 e que "outros achados sugerem que a eficiência da instrução de L2 é durável" ${ }^{17}$ (NORRIS; ORTEGA, 2000, p. 417).

13 "they do not refute the essential claim that Neufeld seeks to make - namely that it is possible for adults to achieve native-speaker levels of proficiency in an L2".

14 "had all received intensive perceptual training that focused their attention on subtle phonetic contrasts between the speech sounds of the target language and those of their L1".

15 "there is considerable evidence to indicate that SL instruction does make a difference".

16 "indicated that focused L2 instruction results in large target-oriented gains, that explicit types of instruction are more effective than implicit types".

17 "further findings suggest that the effectiveness of L2 instruction is durable". 
Outra argumentação a favor do ensino explícito vem de Littlewood (2004, p. 512), que afirma que "é claro que a instrução tem efeitos na aprendizagem no caso daqueles muitos falantes de segunda língua cuja habilidade vem apenas da instrução em sala de aula, suplementada talvez por uma limitada quantidade de prática fora da sala de aula", ${ }^{18}$ que é exatamente o caso do Brasil e, obviamente, o da pesquisa aqui relatada.

Paralelamente à discussão sobre o ensino explícito, está aquela sobre os tipos de conhecimento que o contexto de exposição natural e o de instrução explícita geram, isto é, conhecimento implícito e conhecimento explícito (LITTLEWOOD, 2004). Há três posições principais entre linguistas aplicados: a posição de Não Interface, a de Interface Forte e a de Interface Fraca. A primeira é defendida principalmente por Krashen (1982) e Prabhu (1987, 1999), que minimizam a eficácia da instrução explícita visto que, para esses teóricos, a aquisição da L2 deve acontecer como a de L1, construindo suas interlinguas $^{19}$ (ILs) de maneira natural, sendo apenas expostos ao input. O termo não interface faz referência à impossibilidade de interação entre o que foi aprendido explicitamente por meio de explicações e o que foi adquirido de maneira natural. Para Krashen (1982), a única utilidade da sala de aula de línguas é a de providenciar um ambiente condutível à aquisição, ou seja, a de fornecer grandes quantidades de input compreensive $l^{20}$ aos aprendizes.

A posição antagônica à de não interface é a de interface total, defendida principalmente por DeKeyser $(1997,2003)$. De acordo com essa posição, o conhecimento explícito de uma L2, que é proveniente da instrução explícita, torna-se conhecimento implícito com a prática focalizada na língua. Essa posição, como o nome indica, defende a interação total entre essas duas interfaces do conhecimento:

[a]pesar de o conhecimento adquirido implicitamente tender a permanecer implícito, e o conhecimento adquirido explicitamente tender a permanecer explícito, o conhecimento aprendido explicitamente

18 "it is clear that instruction has effects on learning in the case of those many second language speakers whose ability comes only from classroom instruction, supplemented perhaps by a limited amount of outside-class practice".

${ }^{19}$ Termo cunhado por Selinker (1972), que faz referência à língua do aprendiz, que está em um contínuo que vai do conhecimento apenas da L1 ao conhecimento pleno, como de nativo, da L2.

${ }^{20}$ Comprehensible input. 
pode tornar-se implícito no sentido que aprendizes podem perder a consciência das estruturas com o tempo, e aprendizes podem tornarse conscientes de estruturas do conhecimento implícito ao tentarem acessá-lo, por exemplo, ao aplicá-lo a um novo contexto ou transmitilo verbalmente a uma outra pessoa ${ }^{21}$ (DEKEYSER, 2003, p. 315).

Para fortalecer sua visão, DeKeyser (2003) faz uma breve revisão de nove estudos laboratoriais e quatro em sala de aula, contrastando o ensino explícito e o ensino implícito. Do primeiro grupo, sua conclusão é que "todos os estudos laboratoriais que envolvem uma comparação direta das condiçôes de aprendizagem implícita e explícita mostram uma vantagem para a aprendizagem explícita"22 e também que "a evidência dos experimentos de laboratório, então, é esmagadoramente favorável à aprendizagem explícita” ${ }^{23}$ (DEKEYSER, 2003, p. 324). Semelhantemente, a conclusão sobre a revisão do segundo grupo de estudos é que, "assim como para os estudos laboratoriais, podemos concluir que os estudos em sala de aula que focalizaram estreitamente a distinção implícito / explícito mostraram uma vantagem para a aprendizagem explícita”24 (DEKEYSER, 2003, p. 326).

Há, por último, a posição de interface fraca, defendida principalmente por aqueles que trabalham com a perspectiva de foco na forma ${ }^{25}$ (e.g. DOUGHTY, 2003; DOUGHTY; WILLIAMS, 1998a; DOUGHTY; WILLIAMS, 1998b; DOUGHTY; WILLIAMS, 1998c; ELLIS, 1997, 2001, 2002, 2008a, 2008b; LONG, 2007; LONG; ROBINSON, 1998;

21 "even though implicitly acquired knowledge tends to remain implicit, and explicitly acquired knowledge tends to remain explicit, explicitly learned knowledge can become implicit in the sense that learners can lose awareness of its structures over time, and learners can become aware of the structures of implicit knowledge when attempting to access it, for example for applying it to a new context or conveying it verbally to somebody else".

22 "all laboratory studies that involve a direct comparison of implicit and explicit learning conditions show an advantage for explicit learning".

23 "the evidence from laboratory experiments, then, is overwhelmingly in favor of explicit learning".

24 "just as for laboratory studies, then, we can conclude that the classroom studies that have focused narrowly on the implicit / explicit distinction have shown an advantage in explicit learning".

${ }^{25}$ Focus on form. 
ROBINSON, 2003; WILLIAMS, 2001, 2005; WILLIAMS; EVANS, 1998), que sustenta que aprendizes com conhecimento explícito de alguns aspectos da L2, isto é, adquirido por meio da instrução explícita, têm maior probabilidade de reconhecer esses aspectos no input natural e, consequentemente, fixálos em suas ILs por uma comparação consciente tanto com o que foi captado no input com o que foi aprendido explicitamente, bem como com o que está presente em sua IL.

A pesquisa aqui apresentada, portanto, refuta a posição de não interface, visto que ela exclui a possibilidade de aprendizagem de uma L2 no contexto brasileiro, no qual se insere a presente pesquisa, e admite a validade da visão de interface fraca, uma vez que ela reconhece a aquisição de uma L2 em contexto de LE, mas sem deixar de reconhecer o papel que tem a exposição à língua-alvo. Todavia, é a posição de interface forte que guia esta pesquisa-ação, pois sua tentativa é justamente a de verificar o impacto, efeito e durabilidade da instrução explícita da pronúncia sobre os participantes desta pesquisa.

\section{Metodologia}

Para alcançar os objetivos e responder as perguntas de pesquisa, foi conduzida uma pesquisa-ação de cunho intervencionista. A pesquisa-ação, apesar de ter pequenas variações quanto à sua definição, tem como base as seguintes etapas (ANDRE, 1995; CARR; KEMMINS, 1988; CHIZZOTTI, 2006; Macintyre, 2002; MOITA LOPES, 1996; NUNAN, 1992, para citar alguns):

1. identificação de um problema, de uma situação que exige mudança;

2. coleta de dados para análise;

3. formação de uma hipótese para planejamento da intervenção;

4. intervenção;

5. avaliação dos efeitos da intervenção;

6. disseminação.

Essas etapas se deram da seguinte maneira nesta pesquisa: após a identificação dos problemas no ensino da pronúncia já mencionados, duas turmas de alunos de inglês como LE foram escolhidas como participantes de pesquisa. Ambas as turmas eram de alunos brasileiros, todos entre 11 e 13 anos de idade, cursando o terceiro semestre do curso básico de inglês em uma 
instituição de línguas particular do Distrito Federal, e que teriam aula com a mesma professora, que não é falante nativa de inglês, durante o segundo semestre de 2007, no qual ocorreram as intervençôes. Todos esses alunos foram gravados antes do início do referido semestre letivo lendo um teste diagnóstico elaborado pelo pesquisador. O teste diagnóstico (ou pré-teste) contou com palavras e frases que testaram pelo menos quatro vezes cada som do inglês considerado difícil para falantes de português do Brasil, de acordo com Avery e Ehrlich (1992), Collins e Mees (2008), Godoy, Gontow e Marcelino (2006), Kelly (2000), Yavas (2006) e Zimmer, Silveira e Alves (2009), como mostra a FIG. 1 a seguir. Frases foram incluídas no teste porque, mesmo tratando-se de um estudo no nível segmental, pode haver mudanças segmentais em uma palavra quando ela está inserida em um trecho de discurso, devido à sensibilidade contextual ${ }^{26}$, isto é, o ambiente fonético-fonológico ao seu redor; os sons que vêm antes e depois dela, assim como as ligações e reduções características da fala, fato que esta pesquisa não pretende ignorar. Além disso, a linguagem autêntica está sempre inserida em discurso.

\begin{tabular}{|c|c|c|}
\hline \multicolumn{3}{|c|}{ DIFICULDADES COM CONSOANTES } \\
\hline Som do inglês & Possível erro de aprendiz brasileiro & Exemplos \\
\hline $\begin{array}{c}{\left[\mathrm{p}^{\mathrm{h}}\right]\left[\mathrm{t}^{\mathrm{h}}\right]\left[\mathrm{k}^{\mathrm{h}}\right] \text { no início }} \\
\text { de sílabas tônicas }\end{array}$ & $\begin{array}{c}{[\mathrm{p}][\mathrm{t}][\mathrm{k}], \text { soando como }} \\
{[\mathrm{b}][\mathrm{d}][\mathrm{g}] \text { para falantes nativos }}\end{array}$ & $\begin{array}{l}\operatorname{pin}\left[\mathrm{p}^{\mathrm{h}} \mathrm{In}\right], \text { soando } \\
\text { como [bIn] }\end{array}$ \\
\hline$[\mathrm{t}] \mathrm{e}[\mathrm{d}]$ & {$\left[\mathrm{t} \int\right]$ e $[\mathrm{d} 3]$} & 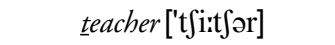 \\
\hline$\left[\mathrm{t} \int\right]$ e $\left[\mathrm{d}_{3}\right]$ & {$\left[\int\right]$ e $[3]$} & catch $\left[\mathrm{k} \int\right]$ major ['mejzər] \\
\hline$[\theta]$ e $[ð]$ & $\begin{array}{c}{[\mathrm{t}],[\mathrm{s}] \text { ou }[\mathrm{f}] \mathrm{e}[\mathrm{d}],[\mathrm{z}] \text { ou }[\mathrm{v}]} \\
\text { respectivamente }\end{array}$ & $\underline{\text { think}}[\mathrm{fI} \mathrm{f} \mathrm{k}]$ this $[\mathrm{ZIS}]$ \\
\hline [ł] pós-vocálico & {$[\mathrm{w}]$} & will [wIw] \\
\hline $\begin{array}{l}\text { Grupos consonantais } \\
\text { em início de palavra }\end{array}$ & Prótese vocálica inicial & $\begin{array}{c}\left.\text { special[Is'pe } \int \partial l\right] \text { strong } \\
\text { [Is'tron] }\end{array}$ \\
\hline$[\mathrm{m}],[\mathrm{n}]$ e $[\mathrm{y}]$ finais & Substituído por vogal nasal & $\operatorname{man}[\mathrm{m} \tilde{x}]$ \\
\hline$[y]$ final & {$[\mathrm{yg}]$} & $\operatorname{sing}[\operatorname{sing}]$ \\
\hline [h] inicial & $\begin{array}{c}\text { Não pronunciado ou adicionado } \\
\text { devido à ortografia }\end{array}$ & house [aws] honest ['honist] \\
\hline$[\mathrm{z}]$ e $[\mathrm{s}]$ & {$[\mathrm{s}] \mathrm{e}[\mathrm{z}]$} & eyes [ajs] basic ['bejzık] \\
\hline
\end{tabular}

${ }^{26}$ Context sensitivity. 


\begin{tabular}{|c|c|c|}
\hline $\begin{array}{l}{[\mathrm{t}],[\mathrm{d}] \text { e }[\mathrm{Id}] \text { no final -ed }} \\
\text { dos verbos regulares }\end{array}$ & [ed] & $\begin{array}{c}\text { stopped ['sta:ped] played } \\
\text { ['plejed] }\end{array}$ \\
\hline [j] e $[w]$ iniciais & {$[\mathrm{I}]$ e $[\mathrm{U}]$} & year $[\mathrm{Iər}] \underline{\text { want }[\mathrm{U} \wedge \mathrm{nt}]}$ \\
\hline$[\mathrm{p}][\mathrm{t}] \mathrm{e}[\mathrm{k}]$ finais & Paragoge vocálico [pi], [ti] e [ki] & too $\underline{k}$ ['tuki] and ['ændi] \\
\hline$[\mathrm{g}]$ & {$[3]$} & getting ['3etın] \\
\hline \multicolumn{3}{|c|}{ DIFICULDADES COM VOGAIS } \\
\hline Som do inglês & Possível erro de aprendiz brasileiro & Exemplos \\
\hline$[\mathrm{i}] \mathrm{e}[\mathrm{I}]$ & {$[\mathrm{I}]$ e $[\mathrm{i}:]$} & beat $[\mathrm{bit}]$ bit $t$ bi:t $]$ \\
\hline$[\mathrm{u}] \mathrm{e}[\mathrm{U}]$ & {$[U]$ e $[u:]$} & fool $l[$ full $f \underline{u} l l[$ fuil $]$ \\
\hline$[æ] \mathrm{e}[\varepsilon]$ & {$[\varepsilon]$ e $[æ]$} & $\operatorname{man}[\mathrm{m \varepsilon n}] \operatorname{men}[\mathrm{mæn}]$ \\
\hline$[æ]$ & [a: & $b \underline{a} d[$ ba:d] \\
\hline [ə] & {$[\mathrm{eI}],[\mathrm{jon}]$ ou $[\mathrm{ou}]$} & 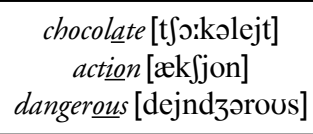 \\
\hline$[\Lambda]$ & {$[\mathrm{U}]$} & luck [luk] \\
\hline$[\Lambda]$ & {$[æ]$} & $f \underline{u} n[f æ n]$ \\
\hline
\end{tabular}

FIGURA 1 - Dificuldade dos brasileiros com os sons do inglês baseado em Avery e Ehrlich (1992), Collins e Mees (2008), Godoy, Gontow e Marcelino (2006), Kelly (2000), Yavas (2006) e Zimmer, Silveira e Alves (2009)

Durante a aplicação do teste, os participantes tiveram a oportunidade de ler as palavras e frases em silêncio antes da gravação, isso para que as gravações representassem a pronúncia dos alunos de maneira mais acurada. Walker (2005, p. 553), ao explicar uma técnica de ensino de pronúncia com gravaçôes, justifica esse procedimento ao dizer que "aprendizes precisam estar completamente familiarizados com o texto antes de gravá-lo, para que eles não sofram de sobrecarga de processamento durante a gravação, o que tira a atenção da pronúncia e os leva a utilizar os seus hábitos da L1". ${ }^{27}$

Após as gravações do teste diagnóstico, deu-se início ao segundo semestre letivo de 2007 e à intervenção. Em uma das turmas (grupo de pesquisa), além de suas aulas normais, os alunos tiveram, durante aquele

27 "learners must be fully familiar with the text before recording it so that they do not suffer from processing overload during the recording, which draws their attention away from pronunciation and leads to reliance on their L1 habits". 
semestre letivo, 15 minutos de aulas explícitas de pronúncia por semana; enquanto que na outra turma (grupo de controle), os alunos tiveram apenas aulas normais:

\section{QUADRO 1}

Os participantes de pesquisa

\begin{tabular}{c|c|c|c}
\hline TURMA & ALUNOS & PROFESSOR & INTERVENÇÃO \\
\hline Grupo de controle & 11 & não-nativo & não \\
Grupo de pesquisa & 17 & não-nativo & sim \\
\hline
\end{tabular}

As aulas extras de pronúncia foram conduzidas pelo pesquisador $\mathrm{e}$ procuraram seguir o modelo comunicativo do ensino da pronúncia ${ }^{28}$ proposto por Celce-Murcia, Brinton e Goodwin (1996, p. 52), que segue os seguintes passos:

- descrição e análise de como o som é articulado;

- prática para distinguir o som de outros sons similares;

- prática controlada;

- prática guiada com feedback;

- prática comunicativa.

Ao final do semestre, os alunos de ambas as turmas foram novamente gravados lendo a mesma lista de palavras e frases do pré-teste (teste diagnóstico) com o intuito de avaliar a intervenção. Finalmente, com vistas a verificar a durabilidade dos possíveis efeitos da instrução explícita, os alunos foram gravados uma última vez 11 meses após o término das intervenções.

\section{Análise de dados}

Cada gravação gerou dados suficientes para serem analisados. Seguem, portanto, os pontos mais importantes da análise do pré-teste (ou teste diagnóstico), do pós-teste imediato e do pós-teste a posteriori.

28 "communicative framework to teach pronunciation". 


\section{Análise do Pré-Teste e Condução da Intervenção}

A primeira análise a ser feita foi a do teste diagnóstico, para verificar quais sons, entre os apontados pela literatura (FIG. 1) como mais difíceis para alunos luso-falantes brasileiros, causariam maior dificuldade para os participantes de pesquisa, definindo, assim, quais sons seriam ensinados nas intervençôes. Consequentemente, após a transcriçãa fonética desses testes, foram contabilizadas as ocorrências de erros em cada som testado e, considerandose os sons com mais de 50\% de ocorrência de erro, é possível constatar que os que causaram maior dificuldade para os participantes da pesquisa foram os seguintes (quadro 2). Para chegar-se ao percentual registrado nos quadros das análises, levou-se em consideração como $100 \%$ o número de vezes que o som ou grupo de sons aparece no teste multiplicado por 28 , que é o número de participantes que fizeram a primeira gravação, 11 na turma de controle e 17 na turma com intervenção.

\section{QUADRO 2}

Sons com mais de $50 \%$ de ocorrência de erro no teste diagnóstico

\begin{tabular}{c|c}
\hline Os sons mais difíceis & Porcentagem de erro \\
\hline$[\mathfrak{x}]$ & $100 \%$ \\
{$[\mathrm{z}] \mathrm{e}[\mathrm{s}]$} & $100 \%$ \\
{$[\mathrm{y}]$} & $100 \%$ \\
\hline$[\mathrm{t}]$ & $95 \%$ \\
{$[\mathrm{u}:]$} & $95 \%$ \\
\hline$[\theta] \mathrm{e}[\mathrm{\gamma}]$ & $93 \%$ \\
\hline$[\mathrm{t}],[\mathrm{d}] \mathrm{e}[\mathrm{Id}] \mathrm{no}-e d$ final & $90 \%$ \\
\hline$[\mathrm{i}:]$ & $83 \%$ \\
\hline$\left[\mathrm{p}^{\mathrm{h}}\right],\left[\mathrm{t}^{\mathrm{h}}\right] \mathrm{e}\left[\mathrm{k}^{\mathrm{h}}\right]$ iniciais & $81 \%$ \\
\hline$[ə]$ & $70 \%$ \\
\hline
\end{tabular}

O teste diagnóstico também possibilitou verificar que as duas turmas escolhidas para a pesquisa estavam no mesmo nível de produção fonéticofonológica. Após contabilizar a média de acertos de cada aluno, pôde-se investigar as médias de cada turma, i.e. $44 \%$ para a turma de pesquisa (desvio-padrão 5,96) e $43 \%$ para a turma de controle (desvio-padrão 5,22), por meio de um teste- $t$ e chegar a um valor $p$ não significativo, de $0,6(t=0,46, d f=26, p=0,6)$, o que indica uma variação tão pequena na média que deve ser creditada à aleatoriedade. 
Feita a análise da primeira gravação e escolhidos os sons a serem tratados, deu-se início às aulas de intervenção, que foram conduzidas pelo pesquisador. O tempo dedicado às aulas de pronúncia foi limitado, pois, das 58 horas de instrução que os alunos tiveram naquele semestre letivo, apenas 4 horas $^{29}$ foram dedicadas às aulas de intervenção, ou seja, menos de $7 \%$ do total. Isso se deu pelo fato de que esta pesquisa não tem por objetivo investigar o ensino da pronúncia como seria feito em um curso de pronúncia, mas, sim, investigar o ensino da pronúncia incorporado às aulas de língua, de maneira mais factível e realista. Esta pesquisa reconhece que não há muito tempo disponível nas aulas de professores que têm de cumprir um conteúdo programático estabelecido pela instituição de ensino, caso da maioria dos professores de língua(s) de cursos livres no Brasil, para que eles se dediquem ao ensino da pronúncia de maneira exclusivista. Portanto, este estudo procurou investigar as consequências de pequenos momentos de instrução explícita da pronúncia que poderiam ser encaixados na agenda didática de professores.

Como mencionado, as aulas de pronúncia seguiram o modelo comunicativo do ensino da pronúncia (CELCE-MURCIA; BRINTON; GOODWIN, 1996), tendo basicamente o seguinte padrão: iniciavam com a apresentação do(s) som(ns) com exercícios de percepção para, depois, passar para exercícios de produção. Exercícios de percepção são importantes como primeira fase da aula porque, enquanto não há conhecimento do som, as palavras da L2 com sons que não existem na L1 serão ouvidas pelos aprendizes com os sons da L1 (AVERY; EHRLICH, 1992). Sobre esse tema, Naiman (1992) e Zimmer, Silveira e Alves (2009) sugerem que, ao serem sensibilizados sobre os sons da L2 por meio da instrução da pronúncia, os alunos passam e ouvir a L2 de maneira diferente, e daí começam a tentar imitar os sons que eles passaram a escutar, estendendo, assim, as aulas de pronúncia para fora da sala de aula. Burns (1992) menciona que isso é na verdade um ciclo, pois, assim como a habilidade de compreender ajuda na produção, a habilidade de produzir também ajuda na compreensão, o que faz a validade do ensino da pronúncia se aplicar não apenas à produção mas também à compreensão. Ainda sobre a importância dos exercícios de percepção, Flege (2007, p. 367) entende que os aprendizes precisam estabelecer novas categorias fonológicas para os sons de uma L2 e que "a percepção das dissimilaridades fonéticas de um som da L2 do som mais próximo da L1 é um fator determinante para uma nova categoria fonética ser estabelecida para o som da L2" - mais um motivo para se beneficiar com a homogeneidade da L1 de aprendizes de inglês no Brasil.

${ }^{29} 15$ minutos semanais durante o semestre letivo. 
Após os exercícios de percepção, as aulas passavam para uma prática controlada do som, com repetição dos sons e de palavras que os contrastam. Essa prática era então seguida por exercícios mais comunicativos, que incorporavam o som trabalhado a trechos de discursos plausíveis de aconteceram em situações reais. Para cada som trabalhado, foram realizados de um a três encontros, dependendo da dificuldade que os alunos tiveram com cada um. As atividades utilizadas nas aulas de pronúncia foram extraídas de Godoy, Gontow e Marcelino (2006), Silva (2005) e Zimmer, Silveira e Alves (2009), por se tratarem de livros didáticos sobre a pronúncia do inglês específicos para alunos brasileiros.

\section{Análise do Pós-Teste Imediato}

A segunda análise foi a do pós-teste imediato, i.e., das gravaçōes realizadas logo após a última aula de pronúncia. A porcentagem da ocorrência de erros foi novamente contabilizada e comparada com aquela do teste diagnóstico. Analisando a queda da ocorrência de erros, já é possível verificar os efeitos positivos da instrução explícita. O QUADRO 3 mostra os sete sons com maior redução na ocorrência de erros entre o teste diagnóstico e o pósteste imediato na turma de pesquisa e na de controle, respectivamente:

\section{QUADRO 3}

Sons com maior redução de ocorrência de erros no pós-teste imediato

\begin{tabular}{|c|c|c|c|c|c|}
\hline \multicolumn{3}{|c|}{ Turma de pesquisa } & \multicolumn{3}{|c|}{ Turma controle } \\
\hline$[\theta][ð]$ & $98 \% \rightarrow$ & $55 \%(43)^{30}$ & {$[\mathrm{t}]$} & $45 \% \rightarrow$ & $36 \%(9)$ \\
\hline$[æ]$ & $100 \% \rightarrow$ & $71 \%(29)$ & [i: $]$ & $86 \% \rightarrow$ & $77 \%(9)$ \\
\hline [ł] & $100 \% \rightarrow$ & $73 \%(27)$ & {$[\mathrm{h}]$} & $24 \% \rightarrow$ & $15 \%(9)$ \\
\hline [u:] & $94 \% \rightarrow$ & $68 \%(26)$ & {$[\mathrm{r}]$} & $39 \% \rightarrow$ & $30 \%(9)$ \\
\hline$[\mathrm{t}][\mathrm{d}][\mathrm{Id}]$ & $90 \% \rightarrow$ & $65 \%(25)$ & {$[\mathrm{I}]$} & $18 \% \rightarrow$ & $9 \%(9)$ \\
\hline [i: $]$ & $81 \% \rightarrow$ & $63 \%(18)$ & [æ] & $100 \% \rightarrow$ & $95 \%(5)$ \\
\hline$[\mathrm{h}]$ & $18 \% \rightarrow$ & $6 \%(12)$ & [ə] & $68 \% \rightarrow$ & $63 \%(5)$ \\
\hline
\end{tabular}

${ }^{30} \mathrm{Em}$ todos os quadros apresentados na análise de dados, os números entre parênteses mostram a queda em pontos percentuais. 
Apesar de também haver diminuição na ocorrência de erros na turma de controle, afinal os alunos continuaram tendo suas aulas de inglês mesmo que sem aulas específicas de pronúncia, não houve nenhum som na turma de controle cuja diferença da ocorrência de erro entre o teste diagnóstico e o pósteste imediato tenha sido maior que 10 pontos percentuais. Da mesma maneira, também não houve nenhum som que não tenha sido tratado na turma com intervenção que tenha sofrido uma queda maior que 10 pontos percentuais.

Conduzindo um teste- $t$ com as médias de acerto de cada turma no pósteste imediato, i.e., $52 \%$ para a turma de pesquisa e $46 \%$ para a de controle, pôde-se verificar que a diferença entre as médias é estatisticamente significativa: $t=2,21, d f=26, p<0,03$. Além disso, o desvio-padrão muito mais alto para a turma de pesquisa (12,96, contra os 5,96 da turma de controle) mostra que houve alunos que se beneficiaram imensamente das intervenções, tendo um desempenho muito superior às médias das turmas.

Esses fatores mostram que alunos podem se beneficiar imensamente de algumas horas, mesmo que poucas, de ensino explícito da pronúncia, contanto que esse ensino seja específico para suas necessidades como falantes de uma determinada L1, neste caso, o português do Brasil.

Outra maneira de se olhar para esses dados é comparar os dois testes de um mesmo participante de pesquisa. Sob essa ótica, foi possível constatar que os alunos com maior redução na ocorrência de erros na turma com intervenção tiveram reduções muito maiores do que os alunos com maior redução da ocorrência de erros na turma de controle, como demonstra o QUADRO 4 a seguir: 
QUADRO 4

Participantes com maior redução de ocorrência de erros entre o teste diagnóstico e o pós-teste imediato

\begin{tabular}{c|c|c|c}
\hline \multicolumn{2}{c|}{ Turma de pesquisa } & \multicolumn{2}{|c}{ Turma controle } \\
\hline Lorena $^{31}$ & $59 \% \rightarrow 35 \%(24)$ & Mário & $62 \% \rightarrow 54 \%(8)$ \\
Fabíola & $50 \% \rightarrow 29 \%(21)$ & Gabriela & $65 \% \rightarrow 58 \%(7)$ \\
Patrícia & $52 \% \rightarrow 32 \%(20)$ & Iolanda & $67 \% \rightarrow 63 \%(4)$ \\
Fábia & $42 \% \rightarrow 25 \%(17)$ & William & $64 \% \rightarrow 60 \%(4)$ \\
Thales & $50 \% \rightarrow 35 \%(15)$ & Yasmin & $56 \% \rightarrow 53 \%(3)$ \\
Sabrina & $54 \% \rightarrow 43 \%(11)$ & Leandro & $54 \% \rightarrow 52 \%(2)$ \\
Nívea & $53 \% \rightarrow 42 \%(11)$ & Alessandra & $44 \% \rightarrow 42 \%(2)$ \\
Maurício & $53 \% \rightarrow 43 \%(10)$ & Beatriz & $58 \% \rightarrow 57 \%(1)$ \\
Mauro & $62 \% \rightarrow 53 \%(9)$ & & \\
Geovana & $51 \% \rightarrow 42 \%(9)$ & & \\
\hline
\end{tabular}

Como pode ser visto, dez dos participantes da turma com intervenção tiveram uma redução de erros superior à do participante da turma de controle que teve maior redução, Mário, que foi de oito pontos percentuais. Além disso, a média da ocorrência de erros no teste diagnóstico é de $57 \%$, para a turma de controle, e $56 \%$ para a turma com intervenção - cifras bem próximas. Já no pós-teste imediato, enquanto a média da ocorrência de erros na turma de controle foi de $54 \%$, a turma com intervenção teve apenas $46 \%$, uma diferença significativa que corrobora a conclusão até aqui traçada de que há efeitos positivos para a instrução explícita de pronúncia na aula de LE.

Por último, foi conduzido um teste-t pareado, comparando a diferença na média de acertos da turma de pesquisa entre o teste diagnóstico e o primeiro pós-teste, constatando-se que a diferença de $44 \%$ para $52 \%$ de acertos é estatiscamente relevante: $t=4,48, d f=16, p<0,0004$.

\footnotetext{
${ }^{31}$ Todos os nomes registrados nos quadros são codinomes, para respeitar o direto de anonimato dos participantes de pesquisa.
} 


\section{Análise do Pós-Teste a Posteriori}

A fim de incorporar uma veia longitudinal a esta pesquisa, após 11 meses do término das intervenções e da gravação do pós-teste imediato, foi aplicado um pós-teste a posteriori, no qual alunos de ambas as turmas foram gravados lendo as mesmas palavras e frases utilizadas nas duas primeiras gravações. Uma comparação entre os dois pós-testes, imediato e a posteriori, revela as seguintes reduçōes significativas na ocorrência de erros:

QUADRO 5

Sons com maior redução de ocorrência de erros entre os pós-testes imediato e a posteriori

\begin{tabular}{c|c|c|c}
\hline \multicolumn{3}{c|}{ Turma de pesquisa } & \multicolumn{3}{|c}{ Turma de controle } \\
\hline$[\Lambda]$ & $38 \% \rightarrow 12 \%(26)$ & {$[\mathrm{t}]$} & $87 \% \rightarrow 78 \%(9)$ \\
{$[\mathrm{t}]$} & $44 \% \rightarrow 21 \%(23)$ & {$[\theta][ð]$} & $81 \% \rightarrow 72 \%(9)$ \\
{$[\mathrm{t}]$} & $73 \% \rightarrow 59 \%(14)$ & $\begin{array}{c}\text { grupos } \\
\text { consonantais }\end{array}$ & $12 \% \rightarrow 6 \%(6)$ \\
{$[ə]$} & $64 \% \rightarrow 54 \%(10)$ & {$[\mathrm{I}]$} & $9 \% \rightarrow 5 \%(4)$ \\
\hline
\end{tabular}

Esses dados são surpreendentes, pois durante os dois semestres de intervalo entre a aplicação dos pós-testes, nenhuma das turmas teve aulas específicas de pronúncia, muito pelo contrário, elas nem mesmo tiveram as mesmas aulas, pois vários alunos precisaram trocar de dias e horários de estudo durante este intervalo de tempo (um ano), estando espalhados em nove turmas diferentes da escola no momento da aplicação do pós-teste a posteriori.

Assim sendo, o mais esperado era que as turmas tivessem taxas de redução de erros parecidas, ou, caso fossem diferentes, que os participantes da turma de controle tivessem uma redução maior, visto que suas proporçôes de erros estavam bem mais elevadas no pós-teste imediato. É como colocar uma pessoa com peso normal e outra muito acima do peso com a mesma dieta saudável durante um período determinado e verificar quem perdeu mais quilos ao final. As chances de quem estava muito além do peso perder mais quilos é maior do que aquele que não tinha sobrepeso. Da mesma maneira, esperavase que, sem expor nenhum participante a aulas explícitas de pronúncia, os da turma de controle tivessem uma melhoria mais significativa. Afinal, o propósito inicial do pós-teste a posteriori era o de verificar a durabilidade dos possíveis efeitos positivos da instrução explícita, e não comparar a evolução dos participantes que não tiveram aulas de pronúncia. Todavia, o que os dados 
acima mostram é que, mesmo sem terem aulas explícitas de pronúncia, os participantes da turma que teve as intervenções continuaram progredindo na área fonético-fonológica mais do que os da turma de controle.

A explicação proposta é que os alunos da turma com as intervenções, por causa das aulas explícitas de pronúncia que tiveram, foram conscientizados acerca da importância de se aprender a pronúncia da L2. Dessa maneira, esses alunos podem ter ficado mais atentos com relação à sua produção fonéticofonológica e com ouvidos mais aguçados para a percepção dos sons do inglês. Além disso, as aulas de pronúncia podem ter criado, além da aprendizagem instantânea de alguns sons averiguada pelo primeiro pós-teste, um conhecimento latente sobre os sons ensinados, de maneira que eles só se materializaram na produção dos alunos quando suas interlínguas se encontravam no estágio apropriado para essa aquisição, sendo, no caso de alguns alunos, até dois semestres depois. As aulas de pronúncia das intervenções podem não ter ajudado alguns dos alunos a pronunciarem os sons ensinados naquele momento, mas certamente os auxiliaram a perceber e automonitorar esses sons em estágios seguintes da aquisição fonético-fonológica.

Novamente comparando os dois pós-testes de cada participante de pesquisa individualmente, é possível averiguar o avanço superior dos participantes do grupo de pesquisa:

\section{QUADRO 6}

Participantes com maior redução de ocorrência de erros entre os pós-testes imediato e a posteriori

\begin{tabular}{c|r|c|c}
\hline \multicolumn{2}{c|}{ Turma de pesquisa } & \multicolumn{2}{c}{ Turma controle } \\
\hline Geovana & $42 \% \rightarrow 26 \%(16)$ & Mário & $54 \% \rightarrow 47 \%(7)$ \\
Murilo & $62 \% \rightarrow 47 \%(15)$ & Yasmin & $53 \% \rightarrow 46 \%(7)$ \\
Rita & $64 \% \rightarrow 53 \%(11)$ & Iolanda & $63 \% \rightarrow 58 \%(5)$ \\
Thales & $35 \% \rightarrow 24 \%(11)$ & Beatriz & $57 \% \rightarrow 52 \%(5)$ \\
\hline
\end{tabular}

Como pode ser facilmente percebido, as taxas de redução da ocorrência de erros na turma de controle quase não foram alteradas, pois a redução maior, que, na análise do primeiro pós-teste, foi de 8 pontos percentuais, passou a 7 no pós-teste a posteriori. Na turma com intervenção, contudo, a queda máxima no primeiro pós-teste, que foi de 24 pontos percentuais, foi maior que os 16 pontos da maior redução no segundo pós-teste. Entretanto, mesmo 
com essa diminuição, fica claro que as diferenças do grupo com intervenção ainda foram bem maiores que as do grupo de controle.

Outra análise que pode ser feita é baseada no aluno com a menor taxa de erros em cada uma das três gravaçóes. Para a turma de controle, as menores taxas de erros foram: $44 \%$ no teste diagnóstico, $42 \%$ no pós-teste imediato e $41 \%$ no pós-teste a posteriori, apresentando uma diferença de apenas três pontos percentuais entre as três gravações. Entre os alunos da turma com as intervençōes, as menores porcentagens de erros são as seguintes: $42 \%$ no teste diagnóstico, $25 \%$ no pós-teste imediato e $24 \%$ no último pós-teste, indicando uma diminuição de 18 pontos percentuais.

Com relação à média da ocorrência de erros, a turma de controle teve uma média aritmética de $57 \%$ de erros no teste diagnóstico, $54 \%$ no pós-teste imediato e $51 \%$ no pós-teste a posteriori, uma diferença de 6 pontos percentuais entre a primeira e a última gravação. A turma com intervenção, por outro lado, teve $56 \%$ de erros na primeira gravação, $46 \%$ logo após as intervenções e 43\% na última gravação, apresentando uma diferença de 13 pontos percentuais.

Por último, foi conduzido um teste- $t$ entre as médias de acerto de cada turma no pós-teste a posteriori e um teste-t pareado, comparando-se as médias da turma de pesquisa no teste diagnóstico e no pós-teste a posteriori. No primeiro, a diferença entre os $57 \%$ de acertos da turma de pesquisa e os $49 \%$ da turma de controle obteve um valor $p$ de 0,02 , em $t=2,05, d f=22, p<0,02$. No teste pareado, a diferença entre os $44 \%$ de acertos no teste diagnóstico e de $57 \%$ no pós-teste a posteriori também foi estatisticamente significativa, com $t=6,41, d f=14, p<0,0001$.

Essas análises apontam que houve não apenas a retenção e a durabilidade da aprendizagem da pronúncia pelos participantes de pesquisa que tiveram as intervenções como também eles, por causa dessas aulas explícitas de pronúncia, continuaram progredindo na área fonético-fonológica de maneira mais satisfatória, mesmo sem ter aulas de pronúncia durante um ano.

\section{Considerações finais}

Como já explicitado nas análises de dados, e retornando aos objetivos da pesquisa, pode-se afirmar que há efeitos positivos na instrução explícita da pronúncia na aula de LE e que esses efeitos têm durabilidade não apenas na retenção como também no desenvolvimento continuado da aquisição da pronúncia da L2. Além disso, é surpreendente o fato de que os benefícios do 
ensino explícito da pronúncia foram alcançados mesmo com uma intervenção limitada quanto ao tempo. Foram realizadas apenas 16 sessões de intervenção de 15 minutos cada, dentro de uma carga horária de 35 aulas de 1 hora e 40 minutos cada, o que representa menos de $7 \%$ do tempo de aula utilizado para o ensino explícito de pronúncia. Isso demonstra que, para que alunos se beneficiem de uma pronúncia mais inteligível, não há necessidade de aulas complementares de pronúncia, visto que, como este estudo apresenta, pequenas porções de instrução explícita enxertadas nas aulas regulares, contanto que específicas e significativas para os aprendizes, trazem benefícios concretos e duradouros. Se as intervenções conduzidas nesta pesquisa duraram apenas um semestre e foram suficientes para demonstrar sua eficácia, o que se dirá do ensino explícito da pronúncia em todos os semestres em que alunos frequentam os cursos de línguas?

Como Collins e Mees (2008, p. 212) argumentam, "muitos professores de línguas sentem que eles não têm tempo suficiente para dar aos seus alunos treinamento prolongado de pronúncia"32 e que, por isso, "alguns, na verdade, não devotam nenhum tempo para isso sequer". ${ }^{33}$ Portanto, aqui está a última etapa necessária em uma pesquisa-ação, que é da disseminação dos resultados, conscientizando professores de línguas de que as aulas de pronúncia não precisam ser prolongadas e nem necessitam de tempo extra no currículo para surtirem efeito. Os alunos não necessariamente precisam ter aulas de pronúncia além de suas aulas de língua, mas suas aulas de língua, se incorporarem instrução e prática fonético-fonológica consistente, explícita e específica, mesmo que por pouco tempo, trarão benefícios comunicativos.

32 "many language teachers feel they do not have sufficient time to give their students prolongued pronunciation training".

33 "some, indeed, devote no time to it whatsoever". 


\section{Referências}

ALMEIDA FILHO, J. C. P.; SCHMITZ, J. R. Glossário de lingüistica aplicada. Campinas: Pontes, 1997.

ANDRE, M. E. D. A. Etnografia da prática escolar. Campinas: Papirus, 1995.

AVERY, P.; EHRLICH, S. Teaching American English pronunciation. Oxford: Oxford University Press, 1992.

BONGAERTS, T. Ultimate attainment in L2 pronunciation: the case of very advanced late L2 learners. In: BIRDSONG, D. (Org.). Second language acquisition and the Critical Period Hypothesis. Mahwah: Lawrence Erlbaum Associates, 1999. p. 133-159.

BURNS, I. M. Pronunciation-based listening exercises. In: AVERY, P.; EHRLICH, S. Teaching American English pronunciation. Oxford: Oxford University Press, 1992. Cap. 12, p. 197-205.

CARR, W.; KEMMIS, S. Teoría crítica de la enseñanza: la investigación-acción en la formación del profesorado. Barcelona: Martinez Roca, 1988.

CELCE-MURCIA, M.; BRINTON, D. M.; GOODWIN, J. M. Teaching pronunciation: a reference for teachers of English to speakers of other languages. New York: Cambridge University Press, 1996.

CHIZZOTTI, A. Pesquisa qualitativa em ciências humanas e sociais. Petrópolis: Vozes, 2006.

COLLINS, B.; MEES, I. M. Practical phonetics and phonology: a resource book for students. Oxon: Routledge, 2008.

DEKEYSER, R. Beyond explicit rule learning: automatizing second language morphosyntax. Studies in Second Language Acquisition, v. 19, n. 2, p. 195-221, 1997. DEKEYSER, R. Implicit and explicit learning. In: DOUGHTY, C. J.; LONG, M. H. (Ed.). The handbook of second language acquisition. Oxford, Massachusetts e Victoria: Blackwell Publishing, 2003. Chap. 11, p. 313-348.

DOUGHTY, C. J. Instructed SLA: constraints, compensations, and enhancement. In: DOUGHTY, C. J.; LONG, M. H. (Ed.). The handbook of second language acquisition. Oxford, Massachusetts e Victoria: Blackwell Publishing, 2003. Chap. 10, p. 256-310.

DOUGHTY, C. J.; WILLIAMS, J. (Ed.). Focus on form in second language classroom. Cambridge: Cambridge University Press, 1998a.

DOUGHTY, C. J.; WILLIAMS, J. Issues and terminology. In: DOUGHTY, C.; WILLIAMS, J. (Ed.). Focus on form in second language classroom. Cambridge: Cambridge University Press, 1998b. Chap. 1, p. 1-12. 
DOUGHTY, C. J.; WILLIAMS, J. Pedagogical choices in focus on form. In: DOUGHTY, C.; WILLIAMS, J. (Ed.). Focus on form in second language classroom. Cambridge: Cambridge University Press, 1998c. Chap. 10, p. 197-262.

ELLIS, R. The study of second language acquisition. Oxford: Oxford University Press, 1994.

ELLIS, R. SLA research and language teaching. Oxford: Oxford University Press, 1997.

ELLIS, R. Investigating form-focused instruction. In: ELLIS, R. (Org.). Formfocused instruction and second language learning: language learning. Oxford: Oxford University Press, 2001. Chap. 1, p. 1-46.

ELLIS, R. Grammar teaching - practice or consciousness-raising? In: RICHARDS, J. C.; RENANDYA, W. A. Methodology in language teaching: an anthology of current practice. Cambridge: Cambridge University Press, 2002. Chap. 15, p 167-174.

ELLIS, R. Explicit form-focused instruction and second language acquisition. In: SPOLSKY, B.; HULT, F. M. The handbook of educational linguistics. Oxford, Massachusetts e Victoria: Blackwell Publishing, 2008a. Chap. 31, p. 437-455. ELLIS, R. The study of second language acquisition. 2. ed. Oxford: Oxford University Press, 2008b.

FLEGE, J. Language contact in bilingualism: phonetic systems interaction. In: COLE, J.; HUALDE, J. I. (Org.). Laboratory phonology 9. Berlim: Mouton de Gruyter, 2007. Chap. 16, p. 353-382.

GODOY, S. M. B.; GONTOW, C.; MARCELINO, M. English pronunciation for Brazilians: the sounds of American English. Barueri: Edtitora DISAL, 2006. KELLY, G. How to teach pronunciation. Harlow: Longman, 2000.

KRASHEN, S. D. Principles and practice in second language acquisition. Oxford: Pergamon Press, 1982.

LITTLEWOOD, W. Second Language Learning. In: DAVIES, A.; ELDER, C. The handbook of applied linguistics. Oxford: Blackwell Publishing, 2004, Chap. 20, p. 501-524.

LONG, M. H. Does second language instruction make a difference? A review of the research. TESOL Quarterly, v. 17, n. 3, p. 359-382, 1983.

LONG, M. H. Problems in SLA. Mahwah: Lawrence Erlbaum Associates, 2007. LONG, M. H.; ROBINSON, P. Focus on form: theory, research and practice. In: DOUGHTY, C.; WILLIAMS, J. (Ed.). Focus on form in second language classroom. Cambridge: Cambridge University Press, 1998. Chap. 2, p. 15-41. 
MACINTYRE, C. The art of action research in the classroom. Londres: David Fulton, 2002.

MCKAY, S. L. Sociolinguistics and second language learning. In: HINKEL, E. (Ed.). Handbook of research in second language teaching and learning. Mahwah: Lawrence Erlbaum Associates, Inc., 2005. Chap. 16, p. 281-299.

MOITA LOPES, L. P. Oficina de linguística aplicada. Campinas: Mercado de Letras, 1996.

MORLEY, J. A multidimensional curriculum design for speech-pronunciation instruction. In: MORLEY, J. (Ed.). Pronunciation pedagogy and theory: new views, new directions. Bloomington: TESOL, 1994. Chap. 5, p. 64-91.

NAIMAN, N. A communicative approach to pronunciation teaching. In: AVERY, P.; EHRLICH, S. Teaching American English pronunciation. Oxford: Oxford University Press, 1992. Chap. 9, p. 163-171.

NEUFELD, G. On the acquisition of prosodic and articulatory features in adult language learning. Canadian Modern Language Review, v. 34, p. 163-174, 1978. NORRIS, J.; ORTEGA, L. Effectiveness of L2 instruction: a research synthesis and quantitative meta-analysis. Language Learning, v. 50, n. 3, p. 417-528, 2000. NUNAN, D. Research methods in language learning. Cambridge: Cambridge University Press, 1992.

PENNINGTON, M. C. Phonology in English Language Teaching. Londres: Addison Wesley Longman Limited, 1996.

PRABHU, N. S. Second language pedagogy. Oxford: Oxford University Press, 1987.

PRABHU, N. S. Teaching is at most hoping for the best. In: WARD, C.; RENANDYA, W. (Ed.). Language teaching: new insights for the language teacher. Singapore: SEAMEO Regional Language Centre, 1999, p. 48-57.

ROBINSON, P. Attention and memory during SLA. In: DOUGHTY, C. J.; LONG, M. H. (Ed.). The handbook of second language acquisition. Oxford, Massachusetts e Victoria: Blackwell Publishing, 2003. Chap. 19, p. 631-678. SELINKER, L. Interlanguage. International Review of Applied Linguistics, v. 10, n. 3, p. 209-231, 1972.

SILVA, T. C. Pronúncia do inglês para falantes do português brasileiro: os sons. Belo Horizonte: FALE/UFMG, 2005.

WALKER, R. Using student-produced recordings with monolingual groups to provide effective, individualized pronunciation practice. TESOL Quarterly: the forum, v. 39, n. 3, p. 550-558, 2005. 
WILLIAMS, J. Learner-generated attention to form. In: ELLIS, R. (Ed.). Formfocused instruction and second language learning: language learning. Oxford: Oxford University Press, 2001. Chap. 8, p. 303-346.

WILLIAMS, J. Form-focused instruction. In: HINKEL, E. (Ed.). Handbook of research in second language teaching and learning. Mahwah: Lawrence Erlbaum Associates, Inc., 2005. Chap. 37, p. 671-691.

WILLIAMS, J.; EVANS, J. What kind of focus and on which forms? In: DOUGHTY, C.; WILLIAMS, J. (Ed.). Focus on form in second language classroom. Nova Iorque: Cambridge University Press, 1998. Chap. 7, p. 139155.

YAVAS, M. Applied English Phonology. Oxoford, Massachusetts e Victoria: Blackwell Publishing, 2006.

YULE, G.; MACDONALD, D. The effects of pronunciation teaching. In: MORLEY, J. Pronunciation pedagogy and theory: new views, new directions. Bloomington: TESOL, 1994. Chap. 7, p. 111-118.

ZIMMER, M.; SILVEIRA, R.; ALVES, U. K. Pronunciation instruction for Brazilians: bridging theory and practice together. UK: Cambridge Scholars Publishing, 2009.

Recebido em janeiro de 2010. Aprovado em março de 2010. 